\title{
Returns to product promotion when consumers are learning how to consume
}

\author{
Zakaria Babutsidze
}

Published online: 5 January 2011

(C) The Author(s) 2011. This article is published with open access at Springerlink.com

\begin{abstract}
This paper presents a computational model of consumer behavior. We consider two sources of product-specific consumer skill acquisition: learning by consuming and consumer socialization. Consumers utilize these two sources in order to derive higher valuations for products they consume. In this framework, we discuss the behavior of returns to advertising relative to changes in product characteristics, such as quality and user-friendliness. The main finding is that, in the case of duopoly, dependence of returns to advertising on product quality is not monotonic as had been suggested by earlier studies. Rather, returns have an inverted U shape, given the quality of the competing product.
\end{abstract}

Keywords Consumer skills • Learning by consuming •

Consumer socialization $\cdot$ Product promotion $\cdot$ Returns to advertising

JEL Classification $\mathrm{D} 11 \cdot \mathrm{M} 37 \cdot \mathrm{C} 63$

\section{Introduction}

It is the nature of the capitalistic free market that the results of producer actions are ultimately anchored to consumer behavior. It is consumers who decide when to buy and what to buy, and how to respond to price or quality changes in products supplied to them. Thus, we believe that the analysis of any economic phenomenon should start with the analysis of consumer decisions.

Z. Babutsidze $(\bowtie)$

MERIT, Maastricht University, Keizer Karelplein 19, 6211 TC, Maastricht, The Netherlands e-mail: babutsidze@merit.unu.edu 
The process of consumer decision-making is complex. It is affected by numerous forces, some more important than others. Our everyday decisions about which products to purchase are largely influenced by our own consumption history, by the information coming from our social network, as well as by the information received from the media.

At the same time, in today's world of advanced technologies, many products need specific consumption skills in order to be utilized to their maximum capacity. We argue that the level of these skills plays an important role in consumer decisions about the composition of a significant share of their consumption baskets. Thus, effects of producer decisions are heavily influenced by the process of skill accumulation by consumers.

This paper looks at the influence of the skill acquisition process on consumers' decisions. We consider the problem of choosing a product among multiple alternatives. We discuss two sources of consumer skill acquisition: learning by consuming and the consumer socialization process. Learning by consuming means that consumers acquire skills along the consumption process, while consumer socialization implies that consumers obtain skill spillovers from their social network.

In this framework, as a new product enters the market, it is met with some initial skill distribution over the population of consumers. Consumers who purchase new products will acquire more skills through the consumption process, and these skills will be further diffused through a socialization process. Thus, consumer purchasing decisions have temporal effects on average skill levels over the population. High rates of initial market penetration will ensure fast acquisition and the diffusion of skills for new products. This implies that a new product will be able to grab higher market shares during the transition to equilibrium. This framework is suitable for analyzing the effects of producer policies that can influence consumer skill levels. We discuss the effects of such policies using the example of product promotion (advertising).

Advertising is recognized as one of the essential activities of a modern firm. Economists, as well as business and marketing academicians, have shown interest in its effects. The main concern has been whether advertising can be used to create barriers to entry and thus to generate a long-run comparative advantage. Views on this issue are not unified: some researchers find that advertising can be effectively used for creating barriers to entry (e.g. Comanor and Wilson 1967, 1979), while others find the opposite (e.g. Erickson and Jacobson 1992). In this paper, we tackle a similar problem. We use an innovative framework in which effects of producer actions are rooted in the micro behavior of consumers. We investigate the manner in which returns to advertising (measured as the gain in market share) depend on quality and userfriendliness of the product when consumers make their product purchases, taking into account their product-specific skills.

Products that we have in mind are those that are relatively durable. They are repeatedly purchased by households and are technologically sophisticated to some extent. This description fits well the group of products called "consumer electronics." This class of products has one more characteristic that makes 
it particularly interesting for us: the products in this category are widely advertised. According to AdvertisingAge, in year the 2007 producers of consumer electronics in the USA spent $50 \%$ of their profits on advertising. ${ }^{1}$ This indicates that producers of consumer electronics rely heavily on advertising as a way of promoting their products.

The paper is organized as follows. Section 2 briefly reviews the existing related literature about learning and socialization among heterogeneous consumers. Section 3 formulates the model of consumer behavior, while Section 4 presents the analysis and results of the model. Section 5 summarizes the paper and provides some concluding remarks.

\section{Individual learning and socialization by consumers}

An important characteristic of the model analyzed in this paper is that consumer behavior evolves through individual learning. Consumers learn individually through experience as well as from social interactions. Individual learning implies heterogeneity among agents, as skill levels might differ across consumers. Models with heterogenous agents are quickly gaining recognition within the discipline. They present an alternative to models characterized by a representative agent. In the late 1980s, criticism of a representative agent emerged concerning its ability to describe correctly the behavior of an economy populated by heterogeneous agents (Kirman 1992). The model presented in this paper does not have a representative agent. In fact, it can be shown that the representative agent cannot be constructed for the economy discussed here.

Similar to agent heterogeneity, individual learning is not new to economics. It has been extensively discussed in the literature. Learning takes many different forms. Detailed discussion of them is outside the scope of the current paper paper; a comprehensive survey can be found in Brenner $(1999,2006)$. One of the most widespread forms of individual learning is learning-by-doing. It has been widely used in economics to explain the effects of innovation and technical change (e.g. Arrow 1962). The idea is that one becomes better at doing something by simply doing it. We have a similar concept in our paper applied to consumer learning: consumers become better at utilizing products that they frequently use. The path of skill level of an individual is called a learning curve (Ebbinghaus 1964). Learning curves have mostly been used in economics to study the rate of producer cost reduction along with increasing experience (Spence 1981; Cabral and Riordan 1997). In this paper, we use the learning curve idea to describe consumer learning.

Apart from learning-by-consuming, agents can acquire consumption skills in other ways. For example, they can help each other out and share the

\footnotetext{
${ }^{1}$ Source: 2007 advertising to sales ratios for 200 largest advertising spending industries, www. adage.com.
} 
skills that they have accumulated. This calls for (non-market) interactions among agents. Modeling non-market interactions among economic agents has a long tradition, but it has become increasingly important in the last two decades. There are various models analyzing interactions among consumers (e.g. Eshel et al. 1996; Cowan et al. 1997). In general, interactions generate feedback loops that affect the decisions of the economic agents. As noted by Gleaser and Scheinkman (2000), the structure of these interactions does matter for the outcome we obtain. In particular, they show that, in the case of local interactions, systems generate more interesting dynamics, have multiple equilibria, and demonstrate the possibility of moving from one equilibrium to another. More contextualized works show that interaction can explain certain interesting phenomena in economics and other social sciences, such as standardization processes (e.g. Arthur 1989; Cowan 1991; Eshel et al. 1998), waves in consumption across the population classes (Cowan et al. 2004), and contagious justice (Alexander and Skyrms 1999).

Non-market interaction among consumers is usually modeled as a socialization process. Consumer socialization has been identified as being important for various social processes, first in sociology (e.g. Roszak 1969) and then in the business literature (e.g. Moschis and Churchill 1978). Sociologists have been concerned with consumer skill acquisition by adolescents through interaction with peers as well as parents, but aspects of life-long learning have been also discussed (Ward 1974). Marketing academicians have also studied consumption skill acquisition of young people, as the learning process is more pronounced in this age-group (Moschis and Churchill 1978). Although some aspects of consumer socialization processes have been discussed in economics, to the best of our knowledge, consumer skill sharing through social processes has not been studied. This paper contributes to filling this gap.

In our paper, we combine learning by consuming with learning through socialization and discuss consumer skill upgrading along the learning curve. The idea of skill acquisition through consumption has been introduced to economics by Witt (2001) under the notion of "learning to consume." The author makes a distinction between the two aspects of learning through consumption: cognitive and non-cognitive. Witt (2001) discusses the subject through the lens of changing preferences and argues that both types of learning (cognitive, as well as non-cognitive) change the consumer preferences and, as a result, the future pattern of consumption of an individual. In this paper, we formalize a part of Witt's learning to consume ideas. In line with Witt (2001), we claim that consuming certain products gives incentives to consume these products again. The mathematical modeling of learning forces in this paper takes quite a general form which can accommodate cognitive (purposeful) learning, as well as non-cognitive learning, which, in our context, might be an accidental discovery of new (unknown to a consumer) features of a product in the process of consumption. The latter part is profoundly different from the definition of non-cognitive learning by Witt (2001), who looks at the matter from the angle of associative learning. There are additional distinctions between forces modeled in this paper and forces considered by Witt (2001). Here we only 
discuss learning in a single product context, rather than learning to consume in general, which is equivalent to forming a habit of consuming. We concentrate on consumers acquiring skills to utilize better separate products. To emphasize these similarities and distinctions, the learning process discussed in this paper is named "learning how to consume."

In the next section, we present a model that uses heterogeneous agents (Kirman 1992), that interact locally outside the market (Cowan et al. 1997). Consumer skills that are acquired through consumption (Witt 2001) are diffused among agents through social interactions (Ward 1974). In this environment, results of any action by producers are anchored to consumer behavior through their effects on individual skill levels. There are temporal feedbacks present in the scheme which determine the size of any effect. We use this model to study the returns on advertising (Mariel and Orbe 2005) and its impact on the market shares of advertisers.

\section{The model of consumer behavior}

Consider an economy with many heterogeneous agents, who have to choose one product every period from an available product set. Each consumer $(s)$ has an idiosyncratic valuation $(v)$ for every product $(n)$ at every time period $(t)$. Valuation of a product for a consumer is the maximum price this consumer is willing to pay.

On the supply side, assume there are many (substitute) products with different qualities $(\lambda)$ offered on the market. We assume that $\lambda$ can be measured in monetary units. We abstract from the differences in prices as well as from the possibility of their temporal change and fix the prices of all the products to be equal to a constant over time.

Consumers are myopic: they make decisions by maximizing one-shot utility. Although we are aware of the shortcomings of the concept of utility maximization, we still use it in this work due to its advantages for the tractability of the formal model. We follow the standard discrete choice literature and model consumer choices probabilistically (Anderson et al. 1992). The probability that consumer $s$ will choose product $n$ at time $t$ is a function of the vector of valuations $\left(\mathbf{V}_{t}^{s}\right)$ that a given consumer holds for a given time period.

Assume that the valuation is multiplicative in two parts: one is the quality of the product $(\lambda)$, the other is the consumer skill level $(k \in[0,1])$, which we assume to be product-specific. If the level of consumer skill is 1 , she can utilize the given product to its maximum capacity, thus her valuation of the product will be equal to the product quality.

Skill levels change over time: consumers learn through consumption and socialization. In modeling individual learning we follow the literature about learning curves pioneered by Ebbinghaus (1964). We assume that learning by consuming occurs at a decreasing rate and specify the learning function as:

$$
k_{m}^{s}=1-\left(1-k_{0}^{s}\right) e^{-\delta m},
$$


where $\delta$ is the speed of learning, $k_{0}^{s}$ is the initial skill level of agent $s$ for the product under discussion, and $m$ is the number of times a product has been consumed prior to (and including) the current one.

From Eq. 1, we can derive the change in skill levels between two subsequent consumptions of the same product

$$
k_{m+1}^{s}-k_{m}^{s}=\gamma\left(1-k_{m}^{s}\right),
$$

where $\gamma=1-e^{-\delta}$.

Using Eq. 2, one can write the law of motion for the valuations of a product while abstracting from the consumer skill sharing process. Recall that $v_{t}^{s}=k_{t}^{s} \lambda$, thus multiplying both sides of the Eq. 2 by $\lambda$ will yield:

$$
v_{m+1}^{s}-v_{m}^{s}=\gamma\left(\lambda-v_{m}^{s}\right) .
$$

Every time period $t$ agent $s$ chooses product $n$ for purchase with the probability $p_{n ; t}^{s}\left(V_{t}^{s}\right)$. This implies that

$$
E_{t}\left(v_{n ; t+1}^{s}\right)=v_{n ; t}^{s}+\gamma_{n}\left(\lambda_{n}-v_{n ; t}^{s}\right) p_{n ; t}^{s},
$$

where $E_{t}(x)$ denotes the expectation about the value of variable $x$ at time $t$.

An important point to note in Eq. 4 is that, besides the product-specific quality level, expected dynamics of valuations also depends on the product specific speed of learning $\left(\gamma_{n}\right)$. This parameter can be interpreted as userfriendliness. If $\gamma_{n}$ is high, the skill acquisition for the product is fast, while in case of a low $\gamma_{n}$ it takes a lot of time before the skill level of a consumer converges to its maximum.

Regarding the socialization process, consider each consumer interacting with a small and constant group of other consumers. We assume that through this interaction some of them can acquire product specific consumer skills. For the sake of tractability, assume that consumers are aligned on a unidimensional lattice (circle) and that each interacts with only two neighbors (one on each side). The consumer can learn about (upgrade skills for) a product through socialization if, and only if, there is at least one consumer in the neighborhood with higher consumer skills for this particular product. We assume that there is a constant rate of learning $(\mu)$ through socialization. We restrict consumers to be able to learn about any product from only one neighbor in any single time period and assume that they are choosing the most skillful consumers in their social networks as their mentors. The rationale for this is that there is a cost of communication and the rate of learning is constant. Thus, maximization of utility implies that one would choose the most skillful neighbor from whom to learn. Ignoring learning through consuming for a moment, the effect of consumer socialization on valuation can be written as

$$
k_{n ; t+1}^{s}=k_{n ; t}^{s}+\mu\left(\max \left(k_{n ; t}^{s-1} ; k_{n ; t}^{s} ; k_{n ; t}^{s+1}\right)-k_{n ; t}^{s}\right) .
$$

It is important to note that $\mu$ is neither product nor consumer specific. In principle, $\mu$ could well be consumer specific, which would reflect the differences in the absorptive capacity of consumers. However, that would further increase the already large parameter space of the model. Instead, 
one can think of $\mu$ as the interaction intensity, which can be thought of as a characteristic of the society.

To combine two forces of consumer learning, we assume that, in spite of the product choices, socialization affects the valuations of all the products in every time period. This means that consumers acquire some skills for every product at every time period (given that they have not reached the highest skill level and they are not the most highly skilled consumers in their neighborhood). Multiplying both sides of Eq. 5 by $\lambda_{n}$ and combining it with the Eq. 4 gives the full specification of the model

$$
E_{t}\left(v_{n ; t+1}^{s}\right)=v_{n ; t}^{s}+\gamma_{n}\left(\lambda_{n}-v_{n ; t}^{s}\right) p_{n ; t}^{s}+\mu\left(\max \left(v_{n ; t}^{s-1} ; v_{n ; t}^{s} ; v_{n ; t}^{s+1}\right)-v_{n ; t}^{s}\right)
$$

It is important to note that the expected law of motion of product valuations is product-specific, as well as consumer-specific. Thus, we have $N \times S$ of these equations (where $N$ is the number of products, and $S$ is the number of consumers in the economy). It is impossible to obtain an analytic solution for this system for any reasonable shape of the probability function. Due to this complication, we use numerical simulations to address the research questions.

\section{Returns to product promotion}

The model specified in Section 3 describes the dynamics of purchasing probabilities of every product for every consumer in the economy. This property seems to be particularly appealing for studying market share dynamics of products on markets with fixed sizes. An important aspect of competing for market shares is product promotion. Producers can promote their product and affect the purchase probabilities of consumers. One widespread tool for product promotion is advertising.

The ground for theoretical work on advertising was laid by Nelson (1974a, b). He considered advertising as a signal of product quality and speculated about the effects of advertising and its differences across types of products. He split the product space in two: "experience goods," the characteristics of which can only be learned through experience, and "search goods," the characteristics of which are observable prior to purchase. Nelson claimed that advertising would have a higher impact on "experience goods," thus expected experience goods to be advertised more. Some time later, Nelson's speculative ideas were formalized by Milgrom and Roberts (1986). They discussed only experience goods and concentrated on the impact of advertising across product quality. Milgrom and Roberts found that high quality brands would have higher incentive to advertise than low quality brands. Empirical support for this finding was provided by Nichols (1998) for the automobile industry. It is evident that academicians have mostly regarded advertising as a tool for signaling the product's high quality, thus the intuitive finding that producers of products with higher quality should have higher incentive to advertise. The following theoretical work (e.g. Landes and Rosenfield 1994) has been built on this intuition. 
Unlike product quality, virtually no work has been done to analyze the effects of variance in product user-friendliness on returns to product promotion. However, one can hypothesize that products that are less user-friendly should benefit more from advertising because they require more extensive use by consumers to acquire an adequate share of their consumption baskets.

In this section, we analyze the effects of parameter changes (product quality and user-friendliness) on returns to product promotion implied by the model of consumer behavior presented in Section 3. ${ }^{2}$ We test the two intuitions specified above (about the effects of product quality and user-friendliness) in environments where consumers are learning how to consume.

In order to discuss the returns to product promotion, we have to introduce a couple of notions and specify the ways in which we measure important variables. We do this in the following section.

\subsection{Measurement}

Measuring a market share As we are studying markets with constant sizes, we can, without a loss of generality, normalize their size to unity. Then, the market share of a product will simply be the cross-average of its purchase probabilities:

$$
h_{n ; t}=\frac{1}{S} \sum_{s=1}^{S} p_{n ; t}^{s} .
$$

Following the discrete choice literature (Anderson et al. 1992), we assume that the probability of product $n$ to be chosen by agent $s$ at time $t$ is described by the multinomial logit function

$$
p_{n ; t}^{s}=\frac{e^{v_{n: t}^{s}}}{\sum_{i=1}^{N} e^{v_{i, t}^{s}}} .
$$

Thus, ultimately market share dynamics depend on the dynamics of valuations. It is easy to verify that as $k_{n}^{s} \rightarrow 1, \forall s, n$, market share distribution becomes time-invariant:

$$
\bar{h}_{n}=\frac{e^{\lambda_{n}}}{\sum_{i=1}^{N} e^{\lambda_{i}}} .
$$

Equation 9 implies that $\bar{h}_{n} \propto e^{\lambda_{n}}$, which effectively means that products with higher quality are guaranteed higher equilibrium market shares. ${ }^{3}$ Equilibrium market share distribution does not depend on any other parameter of the

\footnotetext{
${ }^{2}$ Although in some places throughout the paper we refer to this phenomena as advertising, the modeling takes a general form so the intuitions can be applied to any other type of product promotion.

${ }^{3}$ A model with similar outcome has been analyzed by Kihlstrom and Riordan (1984), while Schmalensee (1978) has presented a model in which products with lower qualities can have higher equilibrium market shares.
} 
model. The rest of the parameters influence only the transition path to the time invariant distribution.

Measuring returns to product promotion As argued in Section 2, in this model the effects of product promotion are anchored to skill acquisition. If the average consumer skill level in the population has not reached its maximum for product $n$, advertising will influence not only the probability of its purchase at the time period when it is advertised, but also during subsequent periods. Higher purchase probability today ensures higher rate of skill acquisition, which in turn influences the purchase probability for the next period. Thus, as long as advertising is undertaken before the average skill level reaches unity, it has a long-lasting effect (Landes and Rosenfield 1994) and influences transitional dynamics to the time invariant market share distribution. On the other hand, if advertising takes place after everybody has learned how to utilize the product to its maximum capacity, it will not have any effect on purchasing probability in subsequent periods.

At this point, we have to recognize that there are many ways to advertise a product, by which we mean that there are many strategies for spending the budget allocated to product promotion. Recent literature puts the emphasis on the search for the optimal temporal advertising policies. It has been found that pulsation advertising policies ${ }^{4}$ are more efficient than uniform advertising policies $^{5}$ on a wide range of markets (Vande Kamp and Kaiser 2000). Mesak and Zhang (2001) provide the theoretical support for this finding on monopolistic markets. In general, however, the search for the optimal temporal policy has not yet yielded any clear recommendation for businesses.

Due to the lack of the theoretical work on the subject, we are confronted with the choice of advertising strategy in order to undertake the investigation into returns to product promotion. Thus, we consider the choice to be whether to advertise or not, rather than how much to advertise, or how to advertise. We assume that, for some fixed cost, which is constant across producers, the producer of product $n$ can influence every consumer's purchase probability in the following manner: if, without advertising, consumer $s$ would buy the product $n$ with the probability given by Eq. 8, with advertising the probability would be

$$
\hat{p}_{n ; 0}^{s}=\frac{A+e^{v_{n ; 0}^{s}}}{A+\sum_{i=1}^{N} e^{v_{i ; 0}^{s}}},
$$

where $A$ is the effect of advertising, which is constant.

It takes simple algebra to notice that $\hat{p}_{n ; 0}^{s}>p_{n ; 0}^{s}$ as long as $A>0$, which we assume is the case. To see the further effects of this mechanism, notice that the probability of purchase positively depends on the valuation of the product (Eq. 10), which is proportional to the skill for the product (as $v_{t}^{s}=k_{t}^{s} \lambda$ ). The

\footnotetext{
${ }^{4}$ Spending large chunks of money at discrete periods of time.

${ }^{5}$ Distributing the advertising budget uniformly over an extended period.
} 
upgrade of those skills positively depends on the purchase probability (Eq. 4). Thus, an exogenous increase in one of these variables creates a feedback loop which increases all the other variables (and ultimately increases itself) in subsequent periods. This is the mechanism by which consumers respond to actions by producers in our framework.

From $\hat{p}_{n ; 0}^{s}>p_{n ; 0}^{s}$ we can deduce that $\hat{h}_{n ; 0}>h_{n ; 0}$. Following the temporal effect argument earlier, we can argue that, as long as $(1 / S) \sum_{s=1}^{S} k_{n ; 0}^{s}<1$, $\hat{h}_{n ; 1}>h_{n ; 1}$, and that, in general, $(1 / S) \sum_{s=1}^{S} k_{n: t-1}^{s}<1 \Rightarrow \hat{h}_{n ; t}>h_{n ; t}$. So, advertising results in a market share gain over an extended period of time if the producer advertises during the first period when her product was put on the market. ${ }^{6}$ Then we can measure the return to advertising as

$$
r_{n}=\sum_{t=0}^{\infty}\left(\hat{h}_{n ; t}-h_{n ; t}\right)
$$

where $r_{n}$ is the return on advertising for product $n$.

\subsection{Analysis}

By looking at the structure of our model, we can derive certain expectations about the effects of model parameters on returns to product promotion in environments where consumers are learning how to consume. The effect of advertising on market share distribution depends on parameter $\gamma$-the userfriendliness of a product. If $\gamma$ is high, the probability gain of a certain size will result in higher average skill level and thus in (on average) higher valuation of the product during the next period compared to when $\gamma$ is low. But at the same time, a higher $\gamma$ would also directly imply higher skills as well as valuation of the product in the next period compared, to a lower $\gamma$. Thus, the size of market share gain due to advertising in case of a lower or higher $\gamma$ is not clear right away.

Returns to advertising also depend on product quality $(\lambda)$. The higher the quality, the more time it takes to reach the equilibrium market share for a given initial valuation and $\gamma$. Therefore, there is potential for higher return on advertising. But at the same time, consider the situation in which only two products are competing on the market. Assume that their qualities and userfriendliness levels are the same. Then without advertising, both products will have half of the market share (if we also assume they start from equal average initial valuations). In this case, advertising of one of the products will result in market share gain, which is the measure of return to advertising. Now assume one of the products is of a much higher quality, ceteris paribus. Consider the case in which the difference between $\lambda$ s is so high that the equilibrium share of the better product is $95 \%$. Will this better product have a higher return

\footnotetext{
${ }^{6}$ The only case in which this statement is not true is when $\forall s v_{n: 0}^{s}=\lambda_{n}$, which we rule out as it does not involve any learning, and thus is not interesting.
} 
to advertising? It is not clear, as the product would quickly acquire its market share even without advertising, so returns to advertising for this scenario would be marginal.

As a result, we can hypothesize that neither product quality nor the level of user-friendliness has a monotonic effect on returns to advertising in our model. We use the $r$ measure to analyze the effects of changes in values of these parameters on returns to product promotion.

There are few possible competition environments in which one can analyze these factors. A market in which there is only one active product (i.e. a product that can increase its market share by advertising for an extended period) is the most simple one. ${ }^{7}$ With one active product on the market, returns to advertising completely depend on the product's own characteristics and the model yields somewhat trivial results: lower product quality and higher userfriendliness result in higher returns to product promotion.

Notice that the effect of the product quality is at odds with intuitions in the earlier literature. The reason is that, in this case competition is not present: although there are incumbent products on the market, they are inactive. To understand why this environment should result in higher returns for lower quality products, consider two products: one of a high quality, the other of a low quality. When they are put on the same market, advertising in both cases will result in an equal size jump in their market shares. After this jump, market share dynamics start converging to the original (without advertising) transition path towards the equilibrium. Due to the model specification, the convergence speed will be higher for the high quality product. This means that the lower quality product will stay off the original transitional path longer, which in principle is the source of returns to advertising.

The intuition behind the result with user-friendliness is simpler: the higher the user-friendliness of a product, the easier the skills are to acquire. Therefore, the equilibrium market share will be reached faster. Because returns to product promotion are measured as the difference between the two scenarios (with advertising and without advertising), reaching equilibrium faster guarantees higher returns.

Including more new products brings new insights, as returns now depend not only on a product's own characteristics, but also on competitors' characteristics. At the same time, they increase the burden of managing the model, as the introduction of every additional competitor increases the number of parameters. As a result, rigorous analysis of markets with many competitors becomes impossible in this framework. Thus we choose to analyze in greater detail the market with only two new products in order to detect intimate links between the parameter changes and returns to product promotion.

\footnotetext{
${ }^{7}$ Recall that, if the product is on the market long enough for the average consumer skill to be sufficiently close to 1 , the producer has no incentive to do costly advertising and it becomes inactive. Thus, this case simply means that there is only one new product on the market. This is equivalent to monopolistic competition, which we can not discuss in its classical form as returns to advertising are measured as the gain in market share.
} 
To demonstrate the results, it is convenient to assume that the number of incumbents on the market is zero, meaning that there are no other rivals to the two new entrants that are engaged in competition for market share. As a consequence, we discuss the case of duopoly.

Consider a new industry arising, having two firms that enter simultaneously. The two firms produce substitute products, but their characteristics $(\lambda$ and $\gamma)$ might differ. One of the problems in discussing the effects of advertising in this setup is that both firms can advertise simultaneously. Therefore, if we choose one of the firms and discuss returns to its advertising, we will have virtually two regimes to analyze: one when the competitor does not advertise and the other when the competitor does advertise. These two regimes might produce not only quantitatively but also qualitatively different responses to advertising. Yet, numerous simulations show that this is not the case in our model: although these two regimes produce quantitatively different results, the qualitative behavior of returns is similar across those regimes, meaning that, if one plots the size of returns against model parameters, the profile has the same shape no matter whether the competitor advertises or not. Their profiles might differ quantitatively, but these differences are extremely small, often negligible.

The reason for this is the following. Consider these two products having the same characteristics $(\lambda$ and $\gamma)$. In this case, if none of the producers advertise, both of the products will have half of the market share from start to end. ${ }^{8}$ If one of the producers advertises, she takes additional market share from the competitor in that period. As a result, skills for that product accumulate faster and this will give temporal advantage to the advertiser's product. This will last for some period until the average skill levels converge to one and market shares of both competitors converge to $50 \%$.

Now consider what happens if the other producer also advertises. Of course, both of them stay with $50 \%$ market share; thus we get the same dynamics of market shares as when neither of the producers was advertising. In this situation, gains from advertising when the competitor advertises and when the competitor does not advertise (in terms of market share gain due to advertising) are exactly equal. The situation becomes asymmetric when characteristics of the products start to differ from each other. However, as long as the differences between the product characteristics are not extremely large, returns to product promotion when the competitor advertises and when she does not are sufficiently close. Thus, in the rest of this section the discussion of one of the scenarios will suffice. Due to simulation simplicity, we choose the scenario when the competitor does not advertise.

If we have two active products on the market, we have pairs of $\lambda \mathrm{s}$ and $\gamma \mathrm{s}$ to work with. But as these products are competing only with each other, intuitively important parameters would be the ratio of $\lambda \mathrm{s}$ and the ratio of $\gamma \mathrm{s}$ rather than the values of single parameters themselves. Thus, we work with

\footnotetext{
${ }^{8}$ Here we assuming that the averages of initial skill levels for both products are equal.
} 
these ratios. This complicates the reporting of results. To solve this problem, we work with peculiar scales for the presentation of simulation outcomes. The axes for the parameter ratios are constructed in such a way that they reach one in the center, which means that the two parameters under discussion have equal values. This splits the axes in two. The right half is a linear scale and reaches some maximum value (e.g. 5, which would mean that the value of the parameter is five times that of the value of the corresponding parameter of the competitor's product), while the left half symmetrically follows the right half and takes values of one over the corresponding value from the right half (thus in this case the left half of the axes would go to $1 / 5$, which would mean that the value of the parameter is five times lower compared to the corresponding parameter of the competitor). To eliminate the differences in results due to the differences in absolute values of the parameter, parameter ratios are created by holding the average of the parameter values constant across the axes. This means that if the ratio of $x$ s being equal to one is created by $x_{1}=2$ and $x_{2}=2$, then the ratio of 3 is created by $x_{1}=3$ and $x_{2}=1$ and the ratio of $1 / 3$ is created by $x_{1}=1$ and $x_{2}=3$.

The left panel of Fig. 1 reports returns to advertising for the different values of the ratios of product user-friendliness (gamma) and quality (lambda). In these simulations, we fix the number of consumers to be 100 and the intensity of communication to be $\mu=0.3$. The range of axes are chosen so that the picture presented displays the relevant portion of the profile. Moving closer towards zero or infinity results in an absolutely flat profile. These are the averages of 40 runs, standard deviations are very small. Every run covers the whole spectrum of $\gamma$ and $\lambda$ ratios. In the beginning of every run, we generate consumers and the initial skill distribution for each of the products, averages of which are equal. After that, we run the economy as long as it takes advertising returns to become negligible for each $\gamma$ ratio- $\lambda$ ratio pair. The next run starts
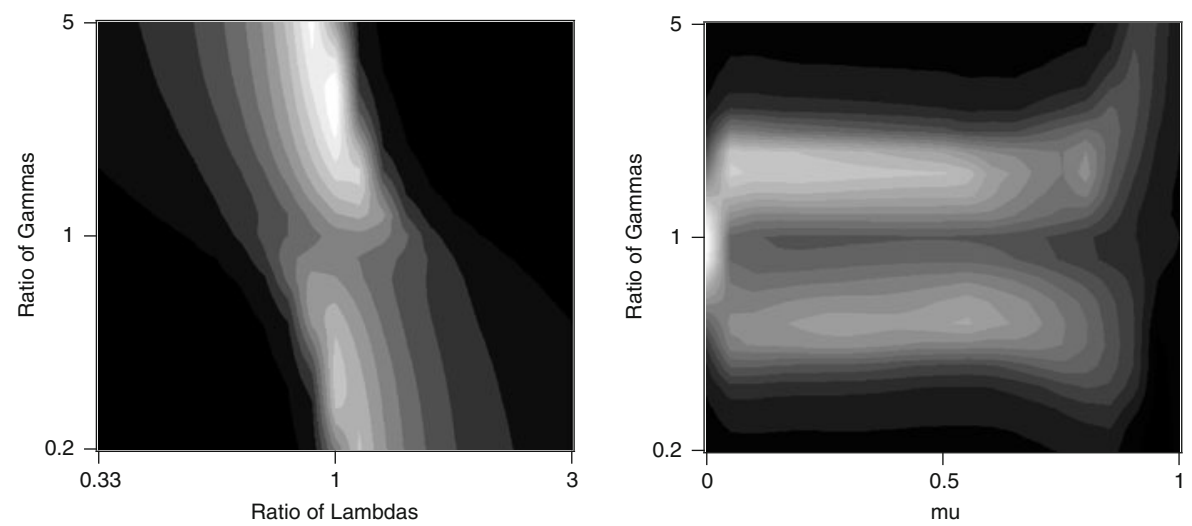

Fig. 1 The case of duopoly: dependence of returns to advertising on quality and user-friendliness (left) and on user-friendliness and communication intensity (right). Lighter shades of gray indicate higher values 
by generating the new skill level distributions. Of course, the averages of every run's skill distributions are equal.

There are a couple of observations one can make about the left panel of Fig. 1. The first is that, no matter what the user-friendliness of the product is, if the quality of the product is sufficiently higher or lower than the quality of the competitor, then returns to advertising are low as compared to the situation when qualities are equal. ${ }^{9}$ The reason for this is that, in both cases, advertising can not affect the skill level development in the economy: if the product is doomed for $0.5 \%$ of the market share, there is little product promotion can do to affect the transitional dynamics to the equilibrium. The same reasoning applies to the symmetric situation: if the equilibrium market share of a product is $99.5 \%$, the product cannot gain much more by advertising during the transition.

The second observation is that, if product qualities are sufficiently close to each other, the dependence of returns to product promotion on userfriendliness of the product has a double-humped shape: starting from the relatively non-user-friendly product, as user-friendliness increases, initially so do returns to advertising, but they fall after some time, reaching a local minimum when user-friendliness parameters of the two products are equal, then they rise and fall again.

The explanation for this phenomenon can be found in the dual nature of the advertising in our model: besides the fact that advertising ensures more early consumers for the product, it also ensures fewer consumers, and slower skill accumulation, for the competitor. Thus, given the equal product qualities, if the product is more user-friendly (relative to the competitor), the major contribution to the returns comes from more consumers consuming this product, while the contribution due to fewer consumers consuming the competitor's product is minor. On the other hand, if the product is (relatively) less user-friendly, the contribution from deterring some consumers from consuming the competitor's user-friendly product becomes much larger, while the contribution from increased consumption of the own product is minor. The dependence of both of these effects on the level of user-friendliness is non-linear. It seems that their joint effect is smaller when the levels of userfriendliness are equal to each other, than when they are (not too) different. This explains the double peaked nature of the returns/gamma profile.

Recall that, in the simulations reported in the left panel of Fig. 1, we fixed the communication intensity, $\mu$. It is important to perform a robustness check to see whether the double-humped shape is due to some peculiar value of communication intensity or whether it persists for the different values of this parameter. In the right panel of Fig. 1, we present the results from similar simulations. In this case, we fix product qualities and vary communication intensity instead. As we saw from the left panel, interesting dynamics are in

\footnotetext{
${ }^{9}$ Although here we report results for one particular $\mu$, the shape of the profile is virtually the same for other values of communication intensity.
} 
place when competitors' products have quality levels which are sufficiently close to each other. So, in this simulation, we fix the ratio of qualities to be one, we vary $\gamma$ s in the same way as in previous simulations and explore the whole space of the values of parameter $\mu$. Everything else stays the same as in the simulations reported in the left panel of Fig. 1. The right panel of Fig. 1 shows that a double-hump shape of returns-user-friendliness profile is present as long as communication levels are away from extremes. This suggests that the qualitative behavior (the shape) of $r-\gamma$ profile is fairly robust to changes in consumer communication intensity.

\subsection{Discussion}

In the previous section, we found that the dependence of returns to advertising on product quality and the level of user-friendliness is not monotonic. This contradicts previous theoretical (e.g. Milgrom and Roberts 1986), as well as empirical (e.g. Nichols 1998) contributions to the analysis of the effects of advertising, which claim that a higher quality would result in higher returns. Does this mean that the current model contradicts the empirical findings? This is an important concern which would imply that our base assumptions about the behavior of consumers are not correct.

To test this, we have to go deeper into the differences between markets used for empirical studies and the markets we analyzed. The monotonic relationship between quality and returns has been empirically found on markets with many diverse producers (e.g. automobiles in the case of Nichols 1998), while we have discussed the case of duopoly. So, if we want to produce comparable results, we have to assume that there are many active products on the market and that all of them have different characteristics. As we argued before, there is no comprehensive way of thoroughly studying the multi-product cases using the current model. If one allows more products on the market, each of them brings two additional parameters. This increases the burden of the model management. In addition, every extra product increases the discrepancy between the results when competitors do not advertise and when they do advertise. If one wants to allow for some of the competitors to advertise while others do not, it would be better to study a model where products have three characteristics instead of two. Introducing a new characteristic for products in this framework will result in a complete reformulation of the model specified in Section 3. A new model will be substantially less parsimonious than the model we are considering in the current paper. Therefore, we choose not to explore this alternative formulation here and keep to the baseline model in order to derive comparable results to Nichols (1998).

To derive the relevant results, we perform the following exercise. Consider the case when there are 20 firms on the market. Assume that their qualities and user-friendliness levels are distributed normally around some means. First, we generate these distributions along with the distribution of the skill levels for each product. Then the algorithm picks every combination of $\lambda$ and $\gamma$ to be the product under consideration. Each constellation of $\gamma-\lambda$ is a different 

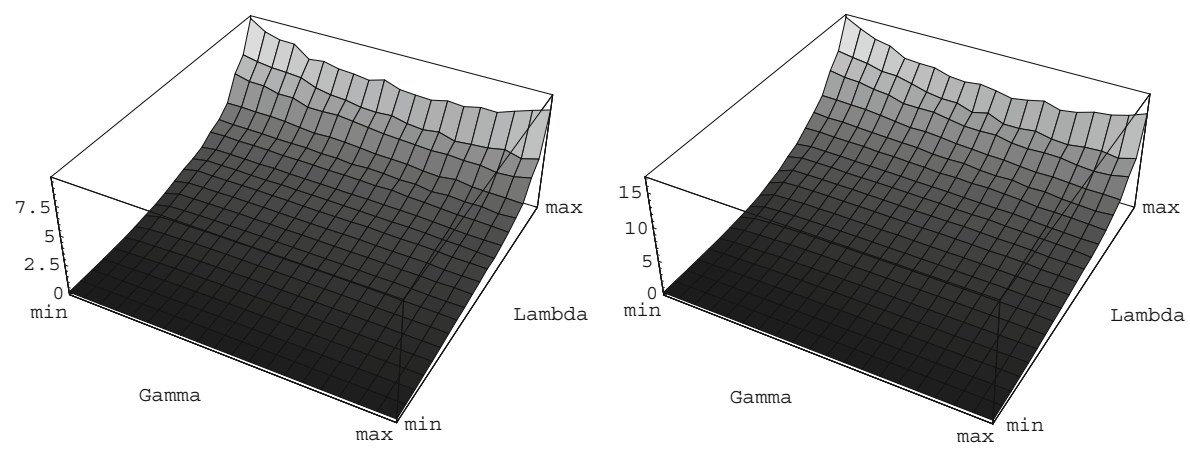

Fig. 2 The case of competitive market: dependence of returns to advertising on quality and userfriendliness when the competitors do not advertise (left) and when they do advertise (right)

scenario. For each of the scenarios, the remaining product qualities are coupled randomly and they comprise the competitor products. As we have $20 \lambda \mathrm{s}$ and $20 \gamma \mathrm{s}$, we have $20 \times 20=400$ scenarios. All these 400 scenarios are run for the fixed distribution of $\lambda s$ and $\gamma \mathrm{s}$ as well as for the fixed distribution of the initial skilled levels. Then we draw another $20 \gamma \mathrm{s}$ and $20 \lambda$ s from the same normal distribution and another 20 skill distributions over consumers and run all 400 scenarios again. We repeat this exercise 40 times and report averages of returns to advertising.

When we have many firms, the quantitative difference between the two scenarios-one when competitors advertise and the other when they do notbecomes more pronounced. Thus, for this (multi-product) case, we report both situations. The left panel of Fig. 2 reports turns to advertising when the remaining 19 producers do not advertise, while the right one reports the results for the case when all the remaining 19 producers advertise. The axes on which we measure product characteristics, represent mere ordering in the relevant distribution, from the minimum to the maximum value of a given characteristic.

Figure 2, shows that on markets with multiple active products, higher quality results in higher returns to advertising, no matter the level of user-friendliness. Thus, our model does not contradict the empirical findings. Rather, it highlights the importance of the market structure and warns that the relation between product quality and returns to advertising might be more complex than what has been believed before.

\section{Summary and conclusion}

In this paper, we have discussed two sources of consumer skill acquisition: learning by consuming and consumer socialization. We have analyzed a population of myopic consumers who socialize locally and utilize the above mentioned two forces to learn how to consume different products. 
In our model, each product on the market has two characteristics: quality and user-friendliness. Quality is the highest valuation consumers can extract from a given good; although it can vary over the product space, it does not vary from consumer to consumer. The long-term market share distribution depends solely on this characteristic. User-friendliness controls the speed of consumer skill acquisition through learning by consuming. This, too, is a product specific characteristic and does not vary from consumer to consumer for a given product. It does not affect the equilibrium market share distribution, but it does affect the speed of transitional dynamics towards it.

The society is characterized by one parameter-communication intensitywhich controls the speed of consumer skill diffusion through the socialization process. Another characteristic of the society is the size of the population, which has not been analyzed in this paper due to its straightforward effects. Larger population size creates greater challenge for the consumer skill diffusion as the socialization process is local.

In this framework, we have discussed the dependence of returns to product promotion on product characteristics. We have analyzed two prior beliefes. One that products with higher quality have higher returns to advertising. The other, that products that are less user-friendly will also have higher returns to product promotion. The major conclusion is that, irrespective of the level of product's user-friendliness, returns to advertising are higher when a product competes with another product of a similar quality. If the competitor is of a considerably higher or lower quality, returns to advertising fall. This contradicts earlier works (e.g. Milgrom and Roberts 1986; Nichols 1998) which claim that the relation between quality and returns is monotonic. We have shown that this model results in a similar pattern when there are many active products on the market. Therefore, we can conclude that earlier empirical findings (Nichols 1998) do not contradict the results of the model presented in this paper. The fact that the current model results in different $r-\lambda$ profiles for different number of active products on the market suggests that dependence of returns to advertising on product quality is influenced by the market structure, a variable that has been omitted from previous analysis. This is in line with Becker and Murphy (1993), who warn that certain effects of product promotion might depend on the market composition.

Another finding of this paper is that the dependence of returns to advertising on the level of user-friendliness has a double-peaked shape when products have similar qualities. This is due to the dual effect of advertising, which means that advertising benefits producers not only by increasing the number of consumers using their products but also by reducing the number of consumers using competitors' products. The sizes of these two effects change at different rates across the change of the levels of user-friendliness. In the case of a product being more user-friendly than that of a competitor, the first effect dominates, while in the opposite case the second effect is the dominant one. What is important here is that the sum of these two effects is higher in each of the cases (when the product is more or less user-friendly compared to the competitor) than when the competitor's product is just as user-friendly. 
Acknowledgements The author is grateful to Robin Cowan, Ulrich Witt and anonymous referees for their detailed comments on the paper. He is thankful to participants of various meetings in Jena, Maastricht and Strasbourg, especially to Tommaso Ciarli, Alex Coad, Alex Frenzel and Marco Valente for their valuable observations. Help from Lina Sonne and Natalia Timus in proofreading the paper is also appreciated.

Open Access This article is distributed under the terms of the Creative Commons Attribution Noncommercial License which permits any noncommercial use, distribution, and reproduction in any medium, provided the original author(s) and source are credited.

\section{References}

Alexander J, Skyrms B (1999) Bargaining with neighbors. J Philos 96:588-598

Anderson SP, de Palma A, Thisse JF (1992) Discrete choice theory of product differentiation. MIT Press, Cambridge

Arrow KJ (1962) The economic implications of learning by doing. Rev Econ Stud 29:15573

Arthur WB (1989) Competing technologies, increasing returns, and lock-in by historical events. Econ J 99:116-131

Becker GS, Murphy KM (1993) A simple theory of advertising as a good or bad. Q J Econ 108:941964

Brenner T (1999) Modelling learning in economics. Edward Elgar, Cheltenham

Brenner T (2006) Agent learning representation: advice on modelling economic learning. In: Tesfatsion L, Judd KL (eds) Handbook of computational economics, vol 2. Elsevier, Amsterdam

Cabral LMB, Riordan MH (1997) The learning curve, predation, antitrust, and welfare. J Ind Econ 45:155-169

Comanor WS, Wilson TA (1967) Advertising and the advantages of size. Am Econ Rev 59:87-98

Comanor WS, Wilson TA (1979) The effects of advertising on competition: a survey. J Econ Lit $17: 453-476$

Cowan R (1991) Tortoises and hares: choice among technologies of unknown merit. Econ J 101:801-814

Cowan R, Cowan W, Swann P (1997) A model of demand with interactions among consumers. Int J Ind Organ 15:711-732

Cowan R, Cowan W, Swann P (2004) Waves in consumption with interdependence among consumers. Can J Econ 37:149-177

Ebbinghaus H (1964) Memory: a contribution to experimental psychology. Dover, New York (Original work published in 1885, translated in 1913)

Erickson G, Jacobson R (1992) Gaining comparative advantage through discretionary expenditures: returns to R\&D and advertising. Manage Sci 38:1264-1279

Eshel I, Samuelson L, Shaked A (1998) Altruists, egoists, and hooligans in a local interaction model. Am Econ Rev 88:157-179

Eshel I, Sansone E, Shaked A (1996) Evolutionary dynamics of populations with a local interaction structure. ELSE working paper. Available via IDEAS. http://ideas.repec.org/p/els/ esrcls/025.html. Accessed 8 Feb 2009

Gleaser EL, Scheinkman JA (2000) Non-market interactions. NBER Working Paper Series, No. 8053

Kihlstrom RE, Riordan MH (1984) Advertising as a Signal. J Polit Econ 92:427-450

Kirman AP (1992) Whom or what does the representative individual represent? J Econ Perspect 6:117-136

Landes EM, Rosenfield AM (1994) The durability of advertising revisited. J Ind Econ 42:263-276

Mariel P, Orbe S (2005) Nonparametric estimation of the effects of advertising: the case of Lydia Pinkham. J Bus 78:649-673

Mesak HI, Zhang H (2001) Optimal advertising pulsation policies: a dynamic programming approach. J Oper Res Soc 52:1244-1255 
Milgrom P, Roberts J (1986) Price and advertising signals of product quality. J Polit Econ 94:796821

Moschis GP, Churchill GA (1978) Consumer socialization: a theoretical and empirical analysis. J Mark Res 15:599-609

Nelson P (1974a) Advertising as information. J Polit Econ 82:729-754

Nelson P (1974b) Economic consequences of advertising. J Bus 48:213-241

Nichols MW (1998) Advertising and quality in the U.S. market for automobiles. South Econ J 64:922-939

Roszak T (1969) The making of a counter culture. Garden City, New York

Schmalensee R (1978) A model of advertising and product quality. J Polit Econ 86:485-503

Spence AM (1981) The learning curve and competition. Bell J Econ 12:49-70

Vande Kamp PR, Kaiser HM (2000) Optimal temporal policies in fluid milk advertising. Am J Agric Econ 82:274-286

Ward S (1974) Consumer socialization. J Consum Res 1:1-14

Witt U (2001) Learning to consume-a theory of wants and the growth of demand. J Evol Econ $11: 23-36$ 